\title{
Espaço público na Atenção Básica de Saúde: Educação Popular e promoção da saúde nos Centros de Saúde-Escola do Brasil
}

Inês Nascimento de Carvalho Reis ${ }^{(a)}$ Ilda Lopes Rodrigues da Silva(b) Julio Alberto Wong Un ${ }^{(c)}$

Reis INC, Silva ILR, Un JAW. Public space in Primary Health Care: Popular Education and healthpromotionatbrasilianhealth-schoolcenters. Interface(Botucatu). 2014;18Supl2:1161-1174.

The conceptual frameworks of this study are health promotion and health education. Their similarities are emphasized, notably the importance of dialogue as a strategy for operational approach. In order to identify the evolution of concepts, practices, and of the institutionalization of health promotion in the perspective of education in primary care in Brazilian National Health System, the issue was investigated in the country's 17 Health School Centers. Overall, 91 people were interviewed (24 managers, 35 professionals and 32 users), and unconventional educational practices in the waiting rooms of the Health School Centers were identified. It was concluded that the visibility of the waiting room as a public space could be enhanced through the appreciation of popular knowledge and collaborative work. Citizens could be encouraged to work creatively, optimizing the available resources.

Keywords: Public space. Popular Education. Health promotion. Primary health care. Waiting Room.
Os marcos conceituais do trabalho são a promoção da saúde e educação em saúde, priorizando suas semelhanças, dentre as quais se destaca a importância do diálogo como estratégia de abordagem operacional. Buscou-se identificar a evolução dos conceitos, das práticas e da institucionalização da Promoção da Saúde, na perspectiva da educação na Atenção Básica de Saúde no Sistema Único de Saúde. O tema foi pesquisado nos 17 Centros de Saúde Escola (CSE) do Brasil, onde se apresentam práticas educativas não convencionais em sala de espera (SE). Na ocasião, foram entrevistados 91 sujeitos (24 gestores, 35 profissionais e 32 usuários). Demonstra-se que a visibilidade das SE como espaço público poderia ser ampliada pela valorização do saber popular e do agir em conjunto, incentivando a cidadania ao trabalhar de forma criativa e otimizando os recursos disponíveis.

Palavras-chave: Espaço público. Educação Popular. Promoção da Saúde. Atenção Básica de Saúde. Sala de Espera.

\footnotetext{
(a) Escola Nacional de Saúde Pública Sergio Arouca, Fundação Oswaldo Cruz. Rua Leopoldo Bulhões, 1480. Manguinhos. Rio de Janeiro, RJ, Brasil. 21041-210.inesreis@ ensp.fiocruz.br (b) Vice-Reitoria de Assuntos Acadêmicos, Pontifícia Universidade Católica do Rio de Janeiro. Rio de Janeiro, RJ, Brasil. ilda@puc-rio.br (c) Centro de Ciências Médicas, Universidade Federal Fluminense. Rio de Janeiro, RJ, Brasil. julio. wong.un@gmail.com
} 


\section{Introdução}

Os avanços cognitivos e a evolução comunicacional no mundo globalizado contemporâneo têm contribuído para, cada vez mais, ampliar-se o conceito de saúde, apesar das práticas não seguirem a mesma velocidade. Um dos marcos atuais é a promoção da saúde, definida na Carta de Ottawa, de 1986, como "um processo de capacitação da comunidade para atuar na melhoria de sua qualidade de vida e saúde, incluindo uma maior participação no controle deste processo. [...] A saúde deve ser vista como um recurso para a vida, e não como objetivo de viver [...]"1 (p. 19).

Para que isso aconteça, acredita-se que é fundamental que os seres humanos valorizem relações éticas e dialógicas em espaços públicos, e não somente privados, onde os saberes devem ser respeitados igualitariamente e cada ato percebido como uma vivência educativa.

Os conceitos de capacitação, participação comunitária e educação tornam-se estratégicos, mas definidos de forma difusa nos documentos oficiais. Lopes ${ }^{2}$ confirmou isso ao analisar as cartas internacionais. Verificou que a participação está implícita em todos os documentos e que a categoria empoderamento está relacionada à essa participação. O autor avaliou que a educação aparece identificada em diversas situações, vinculada tanto ao reforço da participação individual e comunitária, para tomada de decisões políticas favoráveis à saúde, como ao desenvolvimento de habilidades pessoais e sociais.

Observa-se que as Cartas não sugerem o uso de metodologias pedagógicas que incentivem processos dialógicos conscientizadores. Uma confirmação está no fato de o diálogo ter sido mencionado somente na Declaração de Santafé de Bogotá de 1992; mesmo assim, o conceito ainda precisa ser burilado.

No Brasil, o conceito ampliado de saúde vem ganhando cada vez mais força. Os princípios fundantes da promoção da saúde foram anteriores aos famosos movimentos internacionais, estando, inclusive, nas origens da saúde coletiva, como detalha Campos ${ }^{3}$. Mas, somente com a necessidade de estratégias de fortalecimento do Sistema Único de Saúde (SUS), criou-se a Agenda de Compromisso pela Saúde, que culminou no surgimento da Política Nacional de Promoção da Saúde (PNP), em 2006, e na inclusão da temática em outras políticas.

A PNP tem o desafio, como uma das estratégias de produção de saúde, de ser transversal, integradora, intersetorial, equânime, plural no respeito às diferenças entre necessidades, territórios e culturas presentes no país. Procura promover a qualidade de vida e reduzir vulnerabilidades e riscos à saúde e, para tanto, valoriza a participação e o controle sociais na gestão das políticas públicas; e a promoção, informação e educação em saúde. Todavia, define temáticas que priorizam, principalmente, o modelo biomédico e pouco do conceito mais ampliado de promoção da saúde.

Nota-se, portanto, a polissemia na promoção da saúde, que tem sido apontada por estudiosos como Tavares ${ }^{4}$, Lefreve e Lefreve ${ }^{5}$, Buss ${ }^{6}$ e Poland et al. ${ }^{7}$. Recente publicação registrou e avaliou práticas identificadas como de promoção da saúde em 12 países da América Latina, inclusive o Brasil. Verificou que há diversas correntes de pensamentos que impedem a definição de um referencial homogêneo nem a primazia de alguma dessas correntes ${ }^{8}$. A publicação ainda relatou que há vários tipos de atividades com elementos em comum, reconhecendo a interdependência da educação em saúde e da participação comunitária, com a promoção da saúde.

Importante destacar a proximidade entre a promoção da saúde e a educação na área da saúde, o que é mencionado em diversas obras. Muitas vezes elas são complementares, confundidas ou superpostas. Uma confirmação está na Organização Pan-Americana de Saúde propor o aumento da "alfabetização em saúde", entendida como parte integrante da promoção da saúde9. Outra está na existência da União Internacional de Promoção da Saúde e Educação para Saúde (Uipes).

Também Vasconcelos ${ }^{10} \mathrm{faz}$ uma interessante analogia, afirmando que a Educação Popular é uma forma latina de promoção da saúde. Pedrosa ${ }^{11}$, ao analisar a polissemia dos termos relacionados à educação na área da saúde, destaca a importância de suas práticas serem ressignificadas "como processos e estratégias para a promoção da saúde no contexto do SUS" (p. 78). Isso se deve ao fato, como aponta o autor, de que a promoção da saúde tem como pressuposto a mobilização e a 
participação efetiva da sociedade e, como princípio, a autonomia individual e coletiva. Assim, as ações educativas, voltadas para comportamentos saudáveis e para a transformação de cenários vividos, teriam, potencialmente, a comunicação como expressão da educação conscientizadora.

Outro laço comum entre a Educação Popular e a promoção da saúde encontra respaldo na produção do educador brasileiro Paulo Freire. Quando residiu no Canadá, influenciou o movimento da saúde com suas propostas que questionavam as estratégias pedagógicas tradicionais ${ }^{7}$. Para Freire ${ }^{12}$, educação "é comunicação, é diálogo, um encontro de sujeitos interlocutores que buscam a significação dos significados" (p. 76), visando a uma prática transformadora da realidade vivida, baseada no respeito ao educando e na conquista de sua autonomia ${ }^{13}$.

Freire também destaca a importância de o "educador progressista" (oposto ao "bancário" ou tecnicista ou meramente informativo) estar seguro e disponível, para se manter atento à realidade em que vive o educando e às suas percepções, pois a relação entre ambos deve ser uma via de mão dupla, e não uma transferência de conhecimento ${ }^{14}$. Para ele ${ }^{15}$, "não é no silêncio que os homens se fazem, mas na palavra, no trabalho, na ação-reflexão" (p. 92). Menciona, ainda, que esse não é um privilégio dos homens, mas um dever.

Recente estudo observou a aplicabilidade do processo educacional transformador, citando a "docência desterritorializada que procura a saúde [...]"16. A autora vivencia, com um grupo de professores, a prática pedagógica da escola, mas fora das salas de aula, partindo do diálogo, do lúdico, do aprendizado do aluno, indo até onde o cidadão está. Quando se pensa na "desterritorialização" e no diálogo dentro do processo de educação transformadora, também se pensa em Hannah Arendt ${ }^{17}$.

Para Arendt, o educar deve acontecer no diálogo que forma espaços públicos, tendo como perspectiva o pensamento, o despertar de si mesmo e dos outros do sono de irreflexão, abortando preconceitos, evitando a alienação proposta pelo consumismo e a banalização das maldades, opiniões vazias e irrefletidas ${ }^{17,18}$.

Como apontado em Freitas et al. ${ }^{19}$, baseado em Arendt, a massificação contribui para o sentimento de que o homem é descartável, incentiva o isolamento, as relações sociais que privilegiam a aparência, o individualismo, o enfraquecimento do espaço público e das ações políticas. Para Arendt ${ }^{17}, a$ ação política representa o nunca estar só e deve ser construída em qualquer lugar; é o mundo compartilhado, o espaço público, onde as diferenças e a pluralidade podem ser articuladas, e uma ação, uma palavra, pode mudar todo um conjunto.

Dess forma, Pedrosa ${ }^{20}$ defende a ampliação dos espaços públicos, como espaços de exercício do diálogo e de respeito à cultura local, a partir de uma construção compartilhada do conhecimento, um dos princípios da Educação Popular em Saúde. Esta, considerada como "agenciadora de autonomias individuais e coletivas, resgata a alteridade de indivíduos e movimentos na luta pelos direitos humanos, contribuindo para a ampliação do significado dos direitos de cidadania, instituindo esta cidadania na vida das pessoas" 20 (p. 93).

Complementa-se com Vasconcelos ${ }^{21}$, que destaca o diálogo como fator fundamental para a aproximação entre o profissional e o popular, sendo a Educação Popular uma potencial reorientadora de práticas. Para tanto, é necessário o uso de metodologias participativas, como a problematização, conforme proposta por Stotz et al. ${ }^{22}$, baseado no fato de que todos têm opiniões sobre qualquer problema e que a ação contribui para um processo de ensino-aprendizagem cooperativo, colaborando para relações mais igualitárias, trocas de saberes e estabelecimento de laços entre profissionais e comunidade. Nesse contexto, parte-se da realidade e da valorização da cultura popular, diminuindo assim o fosso cultural entre serviços e população, como mencionam Stotz, David e Wong-Un ${ }^{23}$.

Apesar da marcante história da Educação Popular, somente nos últimos anos, iniciou-se o processo de incorporação formal ao SUS, que culminou com a formulação e aprovação da Política Nacional de Educação Popular em Saúde, pelo Conselho Nacional de Saúde, em julho de 2012; política esta que está em fase de implementação.

Outras políticas nacionais de saúde, em especial a de Atenção Básica da Saúde, de 2011; de Promoção da Saúde, de 2006; e de Humanização da Saúde, de 2004; não aprofundam a temática da educação. A primeira destaca a importância de "um espaço de construção de cidadania" e de agir 
em espaços comunitários. A segunda aponta a educação em saúde relacionada a hábitos de vida e responsabiliza as instâncias de saúde na identificação, articulação e apoio às experiências de Educação Popular. Sendo somente a terceira a única que menciona o diálogo, mesmo que somente uma vez, incentivando o aumento do diálogo entre profissionais, e destes com a população e gestores. Nenhuma aborda aspectos pedagógicos.

As fragilidades políticas e conceituais refletem e, ao mesmo tempo, reforçam as fragilidades de ações que incentivem práticas dialógicas e que impulsionem o exercício do cuidado de cada cidadão para consigo e com o coletivo. Um exemplo está no resultado de pesquisa em unidades da saúde da família, que apontou um dos grandes desafios para trabalhar com a abordagem freireana a produção do diálogo libertador a partir de uma educação problematizadora ${ }^{24}$.

Os autores concluem que, embora seja amplamente difundida a importância do diálogo, da humanização da assistência, dos vínculos, do acolhimento nos serviços de saúde, da participação e empoderamento, perpetua-se, ainda, uma comunicação autoritária.

O fato de o setor saúde ter sido historicamente centrado no modelo biomédico contribuiu para que muitas riquezas culturais fossem banidas, sendo fundamental perceber as dissonâncias culturais e as "culturas dos serviços", valorizar a solidariedade e a democratização da sociedade, pois fazemos parte dela, somos feitos por ela e participamos de sua transformação ${ }^{25}$.

Portanto, a falta de precisão conceitual e política, a formação curricular baseada em modelos não dialógicos de educação e a força do modelo biomédico podem contribuir para se compreender a dificuldade dos profissionais de saúde em dimensionar e operacionalizar as intenções expostas nos documentos oficiais.

Acredita-se que a educação dialogada é um imperativo ético. Além de proporcionar o conhecimento formal, que pode favorecer o desenvolvimento social e tecnológico, também, e principalmente incentiva o desenvolvimento de relações éticas, tolerantes, humanizadas, transformadoras.

\section{Metodologia}

$\mathrm{Na}$ busca por uma compreensão da realidade dos CSE com foco na sala de espera, foi realizada a tese de doutorado com pesquisa quali-quantitativa, utilizando a abordagem multimétodos ${ }^{26}$.

Como apontam Bauer e Gaskell ${ }^{27}, "$ "...] a escolha qualitativa ou quantitativa é primeiramente uma decisão sobre a geração de dados e os métodos de análise, e só secundariamente uma escolha sobre o delineamento da pesquisa ou de interesses de conhecimento [...] - e os resultados são construídos nos processos de comunicação" ( $s / p)$, formal e informal, dos discursos, textos, imagens e materiais sonoros ${ }^{28-30}$. Os multimétodos buscam minimizar o fato de que qualquer instrumento é como uma fotografia, "chamusca o real" 31,32 , pois as distorções fazem parte da estrutura da pesquisa ${ }^{33}$.

Assim, estabelecendo um diálogo com os estudiosos em metodologia, a pesquisa, foi embasada nos seguintes instrumentos:

- a observação científica em visita ao campo, que consistiu em registrar o cenário pesquisado, contando com a integração (observação participante), ou não, entre o pesquisador e a realidade estudada, sendo registrada por escrito em diário de campo, em filmagem e fotografia;

- a entrevista semiestruturada, transformada posteriormente em questionário, possibilitando o diálogo e a melhor apreensão de uma realidade a partir da narrativa verbal e da validação do entrevistado.

Foram estudadas diversas possibilidades para selecionar o campo de estudo, adotando critérios reconhecidos pelo SUS, para trazer-lhe contribuições conclusivas. Assim, utilizou-se o Cadastro Nacional de Estabelecimentos de Saúde, de acesso irrestrito on-line, dos anos de 2009 e 2010, quando se identificou o total de 23 Centros de Saúde Escola (CSE) no Brasil.

Essa escolha se deu pelo fato de os CSE terem sido criados para servir de referência para o SUS, notadamente, pela sua responsabilidade com as políticas públicas e a formação de recursos humanos para a Atenção Básica de Saúde, principal porta de entrada do Sistema. 
A pesquisa aconteceu em quatro etapas:

- levantamento de dados on-line, para identificar os contatos telefônicos e perfil institucional. Quando não se obteve informações de um CSE, este foi excluído;

- contatos telefônicos com os gestores de todos os 22 CSE, para avaliar a viabilidade de participação na pesquisa, sendo excluídos os que não eram mais unidades autônomas e/ou nem CSE, perfazendo um universo final para pesquisa de 17 CSE;

- visita de campo a três CSE selecionados por tipo de gestão institucional e de frequência de atividades realizadas em sala de espera de usuários;

- entrevista telefônica com os demais 14 CSE.

Participaram da pesquisa de visita de campo: todos os gestores; outros profissionais que desenvolviam, no momento da pesquisa ou anterior a esta, atividades educativas em sala de espera ou fora dela; assistentes sociais e profissionais que faziam o acolhimento ao usuário; e usuários do serviço, com a seleção aleatória distribuída entre o horário de atendimento da manhã e da tarde. Os profissionais foram indicados por serem considerados pelos gestores, ou entre eles mesmos, como informantes-chave. A pesquisa por telefone, por questões operacionais, aconteceu com os gestores e profissionais informantes-chave que exerciam atividades educativas.

Cabe ressaltar o êxito na receptividade e participação dos entrevistados. Esperava-se entrevistar um gestor e um profissional que exercia atividade educativa por CSE e mais os recepcionistas dos três CSE visitados, o que totalizaria 37 profissionais, além dos usuários das visitas. Mas, a indicação de um profissional a outro, acarretou que, nas duas etapas de coleta de dados, fossem entrevistados 59 profissionais; destes, 23 eram gestores; além de 32 questionários de usuários; totalizando 91 questionários analisados, nos 17 CSE do Brasil.

Diferentes autores, dentre eles Bardin ${ }^{34}$, Marconi e Lakatos ${ }^{35}$, Minayo $^{28,29}$ e Laville e Dionne $^{36}$ serviram de referência para a análise dos dados. Destaca-se que a análise de conteúdo consistiu em traduzir a essência de cada resposta em elementos que, constituindo as unidades de análise, também são chamados de categorias ou unidades de classificação ou de registro ou de sentido, ou seja, palavras, expressões, frases que se referem ao tema ${ }^{36}$.

Para isso, os critérios de inclusão e exclusão de cada elemento levam em consideração serem: pertinentes (coerentes dentro de cada categoria); exaustivos (verificada a classificação e incluídos os subelementos de classificação incerta); precisos (definidos com clareza para não variarem conforme as circunstâncias); e exclusivos (impossibilidade de que cada elemento esteja em mais de uma categoria). Dessa maneira, utilizaram-se os seguintes procedimentos:

- leitura flutuante de todos os questionários, para ter uma visão de conjunto e de particularidades;

- organização das perguntas por temas (promoção da saúde, atividade educativa e sala de espera) e por tipo de entrevistado de cada CSE (gestores, profissionais e usuários);

- leitura de cada resposta, buscando os núcleos de compreensão do texto, chamando-os de elementos;

- quantificação dos elementos, após releitura do material, excluindo os repetidos dentro do conjunto das respostas de cada entrevistado;

- classificação dos elementos, reagrupando e gerando subelementos, quando pertinente;

- agrupamento dos elementos em categorias;

- quantificação dos agrupamentos superiores de análise (categorias ou elementos), após releitura do material, excluindo as eventuais duplas contagens de significados semelhantes nas interpretações dos agrupamentos inferiores (elementos ou subelementos);

- tratamento dos resultados obtidos e interpretação, a partir da estatística dos dados brutos, com retorno aos discursos, correlações dentro de cada discurso e deste com o conjunto, confrontando com o quadro teórico e os objetivos propostos.

Destaca-se que toda pesquisa social tem que pressupor um exercício de escuta e humildade, e um comprometimento com a temporalidade, com a espacialidade, com a busca de transparência da intencionalidade de pesquisador e pesquisado e com a interação entre os diferentes.

Portanto, a complexidade do campo da saúde e as possibilidades de enfrentamento da questão social, reforçam a importância da utilização de uma diversificada gama de métodos e técnicas, desde 
que coerentes, a fim de contribuírem para a ampliação do entendimento sobre uma dada realidade. $\mathrm{O}$ êxito nas entrevistas aumentou o sentimento de responsabilidade social, científica e acadêmica sobre a análise e divulgação dos dados correspondentes.

\section{Resultados}

A pesquisa buscou compreender o significado da promoção da saúde e das atividades educativas para gestores, profissionais e usuários, e como aconteciam na prática dos $\mathrm{CSE}^{26}$.

A promoção da saúde foi percebida como uma visão ampliada de saúde, mas as falas dos entrevistados e as observações nas visitas de campo mostraram que ainda há que se criar e fortalecer estratégias de enfrentamento da questão social, dos determinantes sociais de saúde (DSS), e da reorientação dos serviços, assim como a própria compreensão e operacionalização das propostas da promoção.

Poucos usuários definiram atividade educativa como um processo de compreensão, participação e multiplicação de saber (16\%). Predominou, assim, a transmissão de conhecimentos (72\%), pelos verbos: orientar, aprender, explicar e informar. Alguns, ao invés de definirem, citaram atividades que representavam sua percepção sobre o assunto: palestras, leituras e exercícios físicos e de memória, e bom atendimento, o que sugere uma influência da educação tecnicista predominante na sociedade, como apontado por Freire ${ }^{14}$.

Constatou-se que, no relato espontâneo e não induzido, somente 15\% dos entrevistados correlacionaram promoção da saúde com o desenvolvimento de atividades educativas e informativas.

$\mathrm{Na}$ fala de gestores e profissionais, que exercem atividades educativas, predominou a educação conscientizadora, transformadora e dialógica, associada ou não ao modelo preventivista de saúde, coerente com a proposta da promoção da saúde. Mas, nenhum deles incluiu em sua definição o termo "Promoção da Saúde"; nem apresentou reflexões sobre os distintos modelos educativos conscientizador versus informativo ${ }^{14,37}$; nem distinguiu as modalidades da educação no setor saúde ${ }^{38}$.

Já os profissionais sem vínculo com atividades educativas apresentaram mais componentes da educação como transmissão de conhecimentos. A pouca, ou inexistente, valorização de aspectos pedagógicos nos currículos escolares de diversas categorias de profissionais de saúde pode interferir diretamente nesse resultado, o que reforça a importância de uma política de educação permanente, relacionada ao SUS e ao Ministério da Educação, que já vem ocorrendo desde 2007, mas precisa ser intensificada.

As falas ilustram com riqueza suas percepções, conforme se lê, a seguir:

“É um processo de interação em que ambas as partes aprendem, mas é muito importante o profissional de saúde ter clareza de que é um educador, de que educação é essa, qual a perspectiva que há por trás de cada ação, para ter clareza do seu papel político, conscientizador, como trabalhador social da saúde".

“É uma ação mais ampla que pode trabalhar todas as questões que podem ser transformadoras de atitude e pensamento, e a sala de espera é uma das formas. Toda ação de saúde do CSE deveria ser uma ação educativa, mas isso só acontece nos grupos e na sala de espera, mas quando usam metodologia adequada a isso".

\footnotetext{
“Penso que ninguém educa ninguém, porém temos um papel fundamental no processo de orientação e cuidado da saúde dos usuários, o que envolve ofertar informações, conversar com o usuário para captar se tais informações cabem em sua rotina de vida e o que pensam, e, assim, fazer orientação em saúde, no sentido da busca por emancipação".

“Não é aquela de banco escolar. É a do dia a dia, começa até no ônibus, dando lugar ao mais velho, começa na família, a escola só complementa. Começa dentro do meu serviço, no posto de saúde. Começa desde o banho, aos cuidados com o risco e a vulnerabilidade. Vamos à creche, à escola, para ensinar desde pequititinho até os maiores, na puberdade, na adolescência, desde os cuidados com o alimento à educação sexual".
} 


\begin{abstract}
"Atividades educativas em saúde são as de prevenção, em âmbito bem amplo, desde trabalhar projeto de vida nas escolas, sobre saúde bucal, família e até outras, desde que se esteja educando para outra cultura, para que outras formas sejam possíveis, como valorizar os chás naturais e homeopáticos; isto talvez possa modificar o modelo de atenção do serviço de saúde".
\end{abstract}

Interessante observar que a palavra "participação" só apareceu diretamente nas percepções de dois gestores e um usuário, quando caracterizaram a promoção da saúde. Mesmo assim, só um gestor citou-a sem associá-la à responsabilidade governamental ou aos profissionais de saúde. Por outro lado, a participação também esteve presente na fala de dois gestores, de um profissional, que desenvolve atividade educativa, e de um usuário, quando definiram atividade educativa.

Esse resultado mostra que, na fala espontânea dos profissionais, o tão mencionado processo participativo não necessariamente é prioritário, o que também foi notado por Heidemann et al. ${ }^{24}$.

Quando se perguntou quais eram as atividades que os usuários consideravam como sendo de promoção da saúde nos CSE, pouco mais da metade (54\%) citou palestras sobre prevenção e tratamento de doenças e alguns mencionaram cuidados com a saúde. O restante achou que era a realização de exames (19\%), um bom atendimento (15\%), distribuição de folhetos $(8 \%)$ e um atendimento integral (4\%). Esse resultado apontou para a necessidade de maior divulgação, para os usuários, sobre o que é promoção da saúde e de incentivo à educação conscientizadora.

Por se acreditar que, idealmente, todos os profissionais de saúde, do recepcionista ao gestor, devem ter a postura educativa, fizeram-se perguntas fechadas e abertas, a todos dos 17 CSE, sobre quais as atividades que consideravam de promoção da saúde e/ou educativas. Um CSE não desenvolvia atividades educativas.

A maioria dos gestores dos 16 CSE que tinham atividades educativas ( $71 \%$ ) citou que os centros ofereciam mais de quatro tipos diferentes de atividades aos usuários: grupos agendados (88\%), eventos que promoviam dentro do CSE (65\%), ações na comunidade (59\%) e momento das consultas $(47 \%)$. Aconteciam, geralmente $(76 \%)$, coordenadas por uma equipe multiprofissional (três ou mais profissões). As temáticas eram: pré-natal, diabetes, hipertensão ( $35 \%$ cada); terceira idade $(29 \%)$; reeducação alimentar (24\%); planejamento familiar, puerpério, aleitamento materno, aconselhamento HIV, combate ao tabagismo (18\% cada); arte, saúde escolar, saúde mental, terapia comunitária, Doenças Sexualmente Transmissíveis (12\% cada); diagnóstico social comunitário, direito urbano sustentável, qualidade de vida, família saudável, caminhada e outras atividades físicas, terapia ocupacional, programa do homem, saúde da mulher, adolescente, escovação dentária, fisioterapia, plantas medicinais, orientação farmacêutica, contador de histórias ( $6 \%$ cada). Nota-se, dessa forma, que a maioria está em consonância com prioridades políticas e programáticas do Ministério da Saúde.

As respostas dos profissionais que desenvolviam atividades educativas foram coerentes e complementares às dos gestores, e não houve distinção significativa entre os demais profissionais. Estes citaram que as categorias que mais desenvolviam essas atividades eram assistentes sociais e equipe de enfermagem ( $41 \%$ cada), psicólogo ( $29 \%$ ), médico e nutricionista ( $24 \%$ cada), fisioterapeuta $(12 \%)$, agente de saúde, educador, terapeuta ocupacional, farmacêutico (6\% cada), visto que $65 \%$ atuavam com apoio multidisciplinar. Prevaleciam grupos no horário da manhã (35\%); com periodicidade variável $(41 \%)$, com frequência semanal em somente $18 \%$. Os grupos, geralmente, aconteciam em sala do próprio CSE $(47 \%)$, na comunidade ou em ambos os locais.

Perguntou-se aos entrevistados se as atividades já haviam acontecido também em sala de espera: somente dez responderam, uma vez que destes, sete informaram que não. Mais da metade dos informantes (54\%) declarou que as atividades contavam com a presença de estagiários e $18 \%$ desenvolviam pesquisa e tinham artigos relacionados a ela, demonstrando uma prática típica de CSE.

Buscou-se conhecer como eram utilizadas as salas de espera. Isso porque é um campo empírico que permite analogias e generalizações sobre um espaço público. Por ela passa o principal usuário do SUS, a população pobre, excluída de muitos dos seus direitos, carente de informações e cuidado, e que se sente sem voz, sem poder para lutar por transformações e melhorias da qualidade de vida. A espera 
pode oprimir e a cotidiana presença da televisão na sala de espera pode incentivar valores e consumo alienados e massificantes.

Assim, o espaço corre o risco de expressar, e até incentivar, a sociedade massificada, onde o indivíduo vê seu problema de maneira individualista, sem possibilidade de troca de experiência e de diálogo com o outro; sem contextualização e crítica ampliada, podendo até ser considerado como paciente/paralisado e/ou alienado, em relação aos problemas estruturais que vivencia na instituição de saúde e em sua sociedade.

Quando se descreve o ambiente barulhento, sem conforto e sem interação social, também se evidencia como os poderes institucionais têm lidado com o pobre e com o enfrentamento das manifestações da questão social. O cidadão fica a esperar, sem incentivo e sem voz. Esses tipos de sala de espera são espaços públicos invisíveis ao público!... Acredita-se que, mesmo quando não existir mais espera, continuarão transitando milhões de usuários nos ambientes da ABS, destinados ao inevitável trânsito da demanda.

Dessa forma, ela deve ser entendida como um espaço que expõe a manifestação da questão social e das relações desiguais sociais, econômicas, culturais e de poder, vigentes entre instituição-profissional de saúde, e usuários-cidadãos. Mas a sala de espera pode ser maximizada como um espaço público, de educação dialógica e conscientizadora, utilizando técnicas de multimídias e/ou recreativas e/ou de aprendizado, inclusive para geração de renda.

O estudo mostrou que os trabalhos na sala de espera contavam com equipe multidisciplinar $(41 \%)$, similar às atividades de grupo citadas acima. Interessante é que os usuários (33\% dos que informaram) destacaram o fato de que profissionais não costumavam declarar sua profissão, e os poucos que o faziam eram: assistente social (20\%), psicólogo (13\%) e médico (7\%). Isso também foi relatado na pesquisa de Gomes et al. ${ }^{39}$.

Os gestores que informaram sobre o horário das atividades em sala de espera citaram que aconteciam de manhã (24\%) e de manhã e à tarde (54\%). Apenas um também funcionava à noite. Mencionaram, também, que aconteciam, predominantemente, de duas a três vezes por semana ou semanalmente ( $41 \%$ cada). Alunos realizaram experiência em sala de espera em $35 \%$ dos CSE, podendo, assim, reconhecer-se o papel institucional de escola. A mesma proporção dos CSE tinha trabalhos escritos a respeito (35\%), dos quais 18\% também desenvolveram tecnologia própria para o uso desse espaço.

Quanto às atividades desenvolvidas, foram abordadas diversas categorias temáticas: hábitos saudáveis (49\%), prevenção de doenças (41\%), exercício da cidadania (34\%), cuidado ambiental $(10 \%)$ e outras, selecionadas pelo profissional ou vinculadas a datas comemorativas (17\%).

Foram utilizadas várias técnicas: palestra, conversas e distribuição de folhetos (59\% cada), incluindo álbum seriado (18\%); recreação interativa (contador de história, encenação de higienização em boneca e brinquedoteca - 35\%); filme educativo (29\%) e de entretenimento (24\%); teatro interativo (18\%); e ainda, exercício de alongamento com música, dinâmica de "radialista" com microfone de papel, degustação, oficina de memória, painel de fotos, contando a história das famílias de profissionais e de usuários ( $6 \%$ cada), além de festas. A maioria dos gestores, quando citaram as técnicas adotadas na sala de espera, mencionaram no mínimo duas técnicas (88\%), mostrando a importância da diversidade de recursos nas dinâmicas relacionadas a esse espaço.

As falas espontâneas apontaram como principais vantagens em desenvolver atividades em sala de espera: a democratização do conhecimento, por ser um espaço aberto para todos, contribuindo para a conscientização cidadã e a multiplicação de saberes; a interação social, que amplia as redes sociais; a humanização do serviço, que acolhe, atenua ansiedades e agrega valor ao momento de permanência nas instituições; a organização do serviço, visando conhecer e ampliar demandas, fortalecer a equipe e rever o processo de trabalho; e a qualificação de discentes e profissionais de saúde.

A pesquisa revelou uma convergência de percepção dos gestores e profissionais entrevistados sobre carências do ambiente construído; de recursos humanos; e de apoio institucional para o uso da sala de espera como espaço público, por priorizarem a produção assistencial ao invés de ações educativas. Quanto à falta de apoio, $65 \%$ do total de profissionais informantes, consideravam-se sem apoio, e os 
três que se sentiram apoiados consideraram que o simples fato da instituição não criar obstáculo já era um apoio. Uma possibilidade sobre restrições ao incentivo de atividades conscientizadoras na sala de espera apareceu em uma fala, que destacou que a gestão receia que haja "um levante", o que sugere estudos sobre as relações de poder existentes.

Cabe destacar que poucos profissionais citaram a dificuldade pessoal em trabalhar em um espaço com grande circulação de pessoas, não só usuários, mas colegas de trabalho. Aproveita-se para registrar a importância do perfil individual e da qualificação para desenvolver atividades em sala de espera, como relatado em algumas experiências ${ }^{26,39-42}$.

A maneira de registrar a produção das atividades educativas e de promoção da saúde, desenvolvidas na sala de espera, não foi mencionada como um limitador, mas talvez contribua para que ela seja um espaço público invisível, o que é um desafio a ser enfrentado.

Cabe mencionar que os entrevistados destacaram que o desenvolvimento de atividades em sala de espera seria melhor com: o ambiente mais confortável, de preferência dividido por tipo de atendimento, para facilitar o foco no usuário; o comprometimento, a criatividade e a qualificação do profissional; um trabalho multidisciplinar, com a presença de mais de um profissional, favorecendo a comunicação com o usuário. Técnicas interativas e recursos adequados foram citados como importantes para a qualidade das ações.

Os discursos dos gestores e profissionais entrevistados apontaram a importância do desenvolvimento de atividades em sala de espera, e somente 17\% acharam desnecessárias, especialmente se for um paliativo para ocupar o tempo de espera, mas, mesmo nesses casos, o foco também estava voltado para o aproveitamento efetivo daquele espaço.

Todos os usuários preferiram que a sala de espera tivesse atividades educativas e $23 \%$ queriam que tivesse sempre, inclusive anunciando antecipadamente, para que fossem ao CSE, exclusivamente, para isso:

"Tem que prestar sempre atenção para pegar informações certas. Ajuda a gente a se cuidar. Podiam marcar com antecedência. Por exemplo, toda $4^{\text {a }}$ feira vai acontecer a atividade " $\mathrm{x}$ ", e assim por diante. Ai a gente vem para isso"

"A sala de espera é como se fosse um atendimento, mas que acontece antes do atendimento. Ela ajuda a gente a ir preparada para perguntar e entender o que a médica quer. É como se fosse um preparo para o atendimento: se você sabe mais sobre o assunto pode informar melhor para o médico".

Apesar da arte não ter recebido um foco especial, acredita-se que, além de um mecanismo de comunicação para Educação Popular e respeito à diversidade cultural ${ }^{23}$, também contribui para a saúde menta $\left.\right|^{43}$ e geração de renda. Nenhum dos entrevistados dos 17 CSE citou a realização de oficinas para o desenvolvimento de habilidades manuais que possibilitassem, inclusive, a geração de renda, mas ela apareceu nos grupos fechados. Apesar de também não ter aparecido em nenhum estudo da pesquisa bibliográfica, essa questão é importante para a promoção da saúde, considerando que interfere nos determinantes sociais de saúde e é viável.

Vivências foram relatadas em Reis ${ }^{42}$, que monitorou cinquenta dinâmicas de grupo diferentes na sala de espera; nelas, os eixos de discussão partiam de situações concretas vivenciadas, favorecendo a ida ao CSE também para outras ações, além do atendimento convencional. Na quase totalidade das vivências, as pessoas eram convidadas a participar de alguma confecção artesanal em torno de uma mesa na sala de espera e, enquanto isso, trocavam-se experiências entre profissionais e usuários.

Já neste estudo, observou-se que a maioria das práticas desenvolvidas foi adequada para acontecer no espaço da sala de espera, sendo avaliadas a partir dos seguintes critérios: facilidade em atrair usuários para participar; avaliação das expressões verbais e físicas durante a atividade; e oportunidade para gerar debates promotores de saúde. Algumas práticas (culinária, plantio, confecção de absorvente de pano, cabeleireiro) foram adequadas para suscitar discussões sobre autoestima, hábitos de vida, cuidados individuais, coletivos e com o meio ambiente. Outras promoveram economia doméstica e geração de renda (artesanato com sucata ou a baixo custo, e costura). 
As atividades culturais (teatro e música) e de artes visuais (desenho e pintura) incentivaram entretenimento, inclusive com temas relacionados a saúde, mas sem trocas de experiências. Atividades que exigiam maior concentração (origami) ou "sujeira" das mãos (papel machê) foram menos apreciadas pelos adultos. Todas as dinâmicas favoreceram o bem-estar, a humanização da sala de espera e a aquisição de novos saberes, segundo o depoimento da maioria dos participantes.

Apesar de desejado pelos usuários e apreciado pelos gestores, o trabalho não chegou a ser uma prioridade da gestão institucional, que precisava da assistente social para outras funções gerenciais. Isso inviabilizou a continuidade dessas atividades naquela época, que só voltaram a ser retomadas, por equipe multiprofissional, com prioridade nas palestras acompanhadas de filmes educativos ou apresentações em power point. Confirma-se, assim, a importância de investir e sensibilizar profissionais para o desenvolvimento de ações de fortalecimento criativo e participativo de espaços públicos.

\section{Conclusões}

Independentemente do arcabouço conceitual ou mesmo do jargão que esteja na moda e das disputas de poder que estejam em vigor, as desigualdades estruturais existem e precisam ser enfrentadas. Acreditase na importância da valorização da ética cidadã para um mundo mais justo; e no valor da educação conscientizadora, dialógica e transformadora em espaços públicos formais e informais.

Os resultados da pesquisa refletem a polissemia e as dissonâncias existentes na construção conceitual da promoção da saúde. Isso acontece, inclusive, no reconhecimento da importância de processos participativos e educativos. Contudo, não significa que se efetivem na prática. Investimentos públicos, inclusive na transformação curricular técnica e universitária, precisam ser incrementados.

As práticas educativas exigem inovação para que extrapolem as rotinas diárias, que enfatizam o modelo biomédico em detrimento da integralidade e da participação preconizada nos encontros nacionais e internacionais, e em nossas próprias leis e políticas públicas, que consagram a promoção da saúde e a Educação Popular.

A era da informação vem difundindo a cidadania consciente, que exige comprometimento e transparência nos serviços públicos em geral. Os resultados da pesquisa de campo mostram que bases teóricas e técnicas para práticas transformadoras ainda precisam ser mais incentivadas.

As salas de espera expressam bem as questões sociais vigentes e as relações de poder, devendo ser aproveitadas como um espaço público, de solidariedade, de diálogo e de educação conscientizadora, de incentivo a transformação e ao exercício da cidadania.

Há necessidade de desenvolver técnicas e abordagens específicas, de sensibilidade, empatia e criatividade para o uso desse espaço, não devendo ser enfrentado como um paliativo institucional para o usuário. Incentivar seu uso, independentemente se há espera ou não por um atendimento, segundo os pressupostos da promoção da saúde e da Educação Popular, pode representar avanços sociais, teóricos e políticos preciosos para o nosso país, notadamente para populações com menos oportunidades de trocas de aprendizado, como entre instituições prestadoras de serviços.

Fica uma reflexão: se a realidade dos centros formadores precisa incorporar a amplitude da promoção da saúde e a Educação Popular, imagine-se como estarão as demais portas de entrada do SUS? As notícias e estudos mostram que precisamos incentivar, divulgar e aprimorar práticas criativas e transformadoras.

\section{Colaboradores}

Inês Nascimento de Carvalho Reis participou da coleta de dados, elaboração, discussão e revisão do texto. Ilda Lopes Rodrigues da Silva e Julio Alberto Wong Un participaram das discussões e revisão do texto. 


\section{Referências}

1. Brasil. Promoção da Saúde. Brasília (DF): Ministério da Saúde; 2002.

2. Lopes RC. Promoção da Saúde na perspectiva da Teoria Educacional Crítica: a relevância do empowerment, participação e dialogicidade. Rio de Janeiro: Pontifícia Universidade Católica; 2008.

3. Campos CJG. Método de análise de conteúdo: ferramenta para a análise de dados qualitativos no campo da saúde. Rev Bras Enferm. 2004; 57(5):611-4.

4. Tavares MFL. Promoção de saúde: a negação da negação. Cad Saúde Pública. 2005; 21(5):1612-9.

5. Lefévre F, Lefévre AMC. Promoção de saúde: a negação da negação. Rio Janeiro: Vieira e Lent; 2004.

6. Buss PM. Promoción de la salud y la salud pública. Rio de Janeiro: Fiocruz; 2000.

7. Poland BD, Green LW, Rootman I, editores. Ambiente para promoção da saúde. Londres: Sage; 199 ?.

8. Arroyo HV, editor. La promocion de la salud en América Latina: modelos, estruturas y visión crítica. Puerto Rico: Universidad de Puerto Rico; 2004.

9. Rabello LS. Promoção da saúde: a construção social de um conceito em perspectiva comparada. Rio de Janeiro: Fiocruz; 2010.

10. Vasconcelos EM. Educação popular: instrumento de gestão participativa dos serviços de saúde. In: Caderno de Educação Popular e Saúde. Brasília (DF): Ministério da Saúde, Secretaria de Gestão Estratégica e Participativa, Departamento de Apoio e Gestão Participativa; 2007. p. 18-29. (Série B, Textos Básicos de Saúde).

11. Pedrosa Jl. Promoção da saúde e educação em saúde. In: Castro A, Malo M, editores. SUS: ressignificando a promoção da saúde. São Paulo: Hucitec; 2006. p. 77-95.

12. Freire P. Extensão ou comunicação? Rio de Janeiro: Paz e Terra; 1983.

13. Freire P. Educação e mudança. 5a ed. Rio de Janeiro: Paz e Terra; 1982.

14. Freire P. Pedagogia da autonomia. 18a ed. Rio de Janeiro: Paz e Terra; 2001.

15. Freire P. Pedagogia do oprimido. Rio de Janeiro: Paz e Terra; 1975.

16. Peixoto AG. Educação e trabalho: costuras, tecidos e bordados de uma docência desterritorializada que procura a saúde. Caxias do Sul: Educs; 2007.

17. Arendt H. A condição humana. 10a ed. Rio de Janeiro: Forense; 2008.

18. Souza MGA. Tolerar é pouco? Por uma Filosofia da Educação a partir do conceito de tolerância. Rio de Janeiro: Pontifícia Universidade Católica do Rio de Janeiro; 2006.

19. Freitas $B$, Cuba CMGB, Pereira L. Iniciando um diálogo com o pensamento arendtiano: reflexões sobre a ação política no espaço público. O Social em Questão. 2007; 16(16):41-52.

20. Pedrosa Jl. Cultura popular e identificação comunitária: práticas populares no cuidado à saúde. In: Martins $C M$, Stauffer $A B$, editores. Educação e saúde. Rio de Janeiro: Fiocruz, Politécnico; 2007. p. 35-70.

21. Vasconcelos $E M$. Redefinindo as práticas de saúde a partir de experiências de educação popular nos serviços de saúde. Interface (Botucatu). 2001; 5(8):121-6.

22. Stotz EN, David HMSL, Bornstein VJ. Educação popular em saúde. In: Martins CM, Stauffer AB, editores. Educação e saúde. Rio de Janeiro: Fiocruz, Politécnico; 2007. p. 35-70.

23. Stotz EN, David HMSL, Wong-Un JA. Educação popular e saúde - trajetória, expressões e desafios de um movimento social. Rev APS. 2005; 8(1):49-60. 
24. Heidemann IBS, Boehs AE, Wosny AM, Stulp KP. Incorporação teórico-conceitual e metodológica do educador Paulo Freire na pesquisa. Rev Bras Enferm. 2010; 63(3):416-20.

25. Wong-Un JA. Fazer do amor uma cidade. Fazer o amor numa cidade: a presença do social e do cultural no cuidado em saúde. In: Fiocruz. Curso de formação de facilitadores de educação permanente em saúde: unidade de aprendizagem - análise do contexto da gestão e das práticas de saúde. Rio de Janeiro: Fiocruz; 2005. p. 49-64.

26. Reis INC. Espaços públicos invisíveis: perdas e conquistas na Promoção da Saúde. Rio de Janeiro: Pontifícia Universidade Católica; 2012.

27. Bauer MW, Gaskell G. Pesquisa qualitativa, contexto, imagem e som. 5a ed. Rio de Janeiro: Vozes; 2002.

28. Minayo MCS. O desafio do conhecimento. 11a ed. São Paulo: Hucitec; 2008.

29. Minayo MCS. Pesquisa social. 25a ed. Rio de Janeiro: Vozes; 2007.

30. Deslandes SF. Violência no cotidiano dos serviços de emergência hospitalar: representações, práticas, interações e desafios. Rio de Janeiro: Fiocruz; 2000.

31. Krauss R. O fotográfico. Barcelona: Gustavo Gili; 2002.

32. Barthes R. A câmara clara. Rio de Janeiro Nova Fronteira; 1984.

33. Bourdieu P. Pour um savoir engagé. França: Le Monde diplomatique; 2002. [cited 2007 Oct 23]. Available from: http://www.monde-diplomatique.fr/2002/02/Bourdieu

34. Bardin L. Análise do conteúdo. Portugal: Impressão Loyola; 2010.

35. Marconi MA, Lakatos EM. Metodologia científica. 5a ed. São Paulo: Atlas; 2009.

36. Lavilla CDJ. A construção do saber. Porto Alegre: Artmed; 1999.

37. Davini MC. La formación docente en cuestión: política y pedagogia. Argentina: Paidós; 1995.

38. Carvalho MAP. Construção compartilhada do conhecimento: análise da produção de material educativo. Caderno de Educação Popular e Saúde. Brasília (DF): Ministério da Saúde, Secretaria de Gestão Estratégica e Participativa, Departamento de Apoio e Gestão Participativa; 2007. p. 91-101.

39. Gomes AMA, Albuquerque CM, Moura ERF, Silva RM. Sala de espera como ambiente para dar informações em saúde. Cad Saude Colet. 2006; 14(1):17-8.

40. Teixeira ER, Veloso RC. O grupo em sala de espera: território de práticas e representações em saúde. Texto Contexto Enferm. 2006; 15(2):320-5.

41. Veríssimo DS, Valle ERM. Grupos de sala de espera no apoio ao paciente somático. Rev SPAGESP. 2005; 6(2):28-36.

42. Reis INC. Promoção da saúde na sala de espera de um centro de saúde. Deb Soc. 2002; 61:129-44.

43. Coqueiro NF, Vieira FRR, Freitas MMC. Arteterapia como dispositivo terapêutico em saúde mental. Acta Paul Enferm. 2010; 23(6):859-62. 
Reis INC, Silva ILR, Un JAW

Reis INC, Silva ILR, Un JAW. Espacio público en la Atención Básica de Salud: Educación Popular y promoción de la salud en los Centros de Salud-Escuela de Brasil. Interface (Botucatu). 2014;18 Supl 2:1161-1174.

Los marcos conceptuales del trabajo son la promoción de la salud y la educación en salud, priorizando sus semejanzas entre las que se destaca la importancia del diálogo como estrategia de abordaje operativo. Se buscó la identificación de la evolución de conceptos, prácticas y institucionalización de la Promoción de la Salud, en la perspectiva de la educación en la Atención Básica de Salud en el Sistema Brasileño de Salud. El tema se investigó en los 17 Centros de Salud-Escuela (CSE) de Brasil, en donde se presentan prácticas educativas no convencionales en sala de espera (SE). Se entrevistaron 91 personas (24 gestores, 35 profesionales y 32 usuarios). Se demuestra que la visibilidad de las SE como espacio público podría ampliarse por medio de la valorización del saber popular y del actuar en conjunto, incentivando la ciudadanía a trabajar de manera creativa optimizando los recursos disponibles.

Palabras clave: Espacio público. Educación Popular. Promoción de la Salud. Atención Básica de Salud. Sala de Espera.

Recebido em 06/11/2013. Aprovado em 26/09/2013. 
